\title{
Prostitution and the ideal state: a defense of a policy of vigilance
}

\author{
Agustín Vicente \\ Ikerbasque: Basque Foundation for Science / \\ Linguistics and Basque Studies Department, University of \\ the Basque Country, UPV/EHU (Spain) \\ agustin.vicente@ehu.eus
}

\begin{abstract}
The debate concerning prostitution is centered around two main views: the liberal view and the radical feminist view. The typical liberal view is associated with decriminalization and normalization of prostitution; radical feminism stands in favor of prohibition or abolition. Here, I argue that neither of the views is right. My argument does not depend on the plausible (or actual) side effects of prohibition, abolition, or normalization; rather, I am concerned with the ideals involved. I will concede to liberals their claim that prostitution is not harmful in itself. Yet, I will argue that prostitution cannot be thought of as "just another job”. Even if prostitution is not harmful in itself, it can do much harm. I will argue that a policy of vigilance is the most adequate one to adopt with regard of prostitution, given the risk of harm associated with prostitution. A policy of vigilance tries to discriminate between those who take a certain course of action willingly and those who do not. It puts no restraints on those who exercise their genuine will, but protects those who are openly or subtly coerced.
\end{abstract}

\section{Introduction}

The debate, public or academic, concerning prostitution is centered around two main views: the liberal view and the radical feminist view. The typical liberal view is associated with depenalization and normalization of prostitution; radical feminism stands in favor of prohibition or abolition. Certainly these are not the only views that different members of society hold with regard to the issue, but it does seem clear that they are the most argued for and respected positions in the public debate; and it seems clear from the vast majority of the academic literature on the subject that they are the 
only ones admitted as reasonable in the academic discussion. The typical liberal view is associated with the depenalization and normalization of prostitution; radical feminism stands in favor of prohibition or abolition. Typically, liberals ${ }^{1}$ argue that prostitution is not harmful per se (e.g., Nusbaum, 1998; Abel, 2010; Moen, 2014). What is really harmful, and devastatingly so, they claim, is the way prostitution has typically been practiced: in conditions of near-slavery, marginalization, and stigmatization. However, such conditions are only "background conditions", so to speak: they are not constitutive of prostitution, which consists merely of the exchange of sexual practices for money. Liberals think that stigmatization, marginalization and the other associated ills, are not connected with what prostitution, or sex work, actually consists of. They claim that stigmatization, marginalization, and the harm associated with them, are only the result of the way our societies react to prostitution and the way prostitution is typically practiced—often in extremely depressing and demeaning conditions. Therefore, these circumstances can be treated as external: they are not derived from the "job" itself. Liberals also tend to think that the harm associated with prostitution can be attributed to these external factors alone ${ }^{2}$. Thus, the ideal for our society should be to regulate and normalize exchanges of sex for money, treating them in all respects as any other similar exchange, i.e., work.

Radical feminists, in contrast, typically take prostitution to be evil in itself (e.g., Barry, 1995; Dworkin, 1997; Farley, 2004; Sullivan, 2007). It is intrinsically a form of violence against women: a way of perpetuating men's dominance in society. Behind the alleged aseptic exchange of sex for money lies a relation of power in which women are required to sacrifice their sexual autonomy to men's whims. Women are simply usedand at the same time despised — and the fact that they can be thus used reinforces the view that women in general are objects at men's disposal. Although many prostitutes claim that they freely choose to do what they do, radical feminists contend that "a gender power dynamic is intrinsic to prostitution” (Sullivan, 2007: 37), and that it is simply not true that women freely choose to sell their bodies for $\operatorname{sex}^{3}$. Radical feminists

\footnotetext{
${ }^{1}$ Not all liberal views are of this sort: see, e.g., de Marneffe (2010).

${ }^{2}$ See, e.g., Martin Moen (2014: 80): "If my arguments in this paper are sound, we should be open to the possibility that prostitutes are harmed, not because prostitution is harmful, but because society at present seriously wrongs prostitutes”.

${ }^{3}$ There are of course more nuanced views within the feminist camp. For instance, Yolanda Estes (2001) holds that prostitution is morally wrong because it objectifies both prostitute and client (the client uses the
} 
deny that prostitutes as such can be “agents”, i.e., people with choice, even when there is an "appearance of choice” and so an appearance of consent (Barry, 1995). According to radical feminism, the ideal for our society should be the complete eradication of prostitution.

This paper concerns the ideal state we should strive for with regard to prostitution. By “ideal state”, I mean a morally correct state of affairs in which harm is effectively minimized (that is, the ideal state implies that harm is minimized, but also that the state does not violate moral principles we regard as reasonable). Liberals hold that such an ideal state is reached when sex work is practiced and treated by the community at large as just another job. Radical feminism, in turn, maintains that the ideal state is only reached when prostitution disappears as a real possibility. I will argue that neither of the two views, liberal or radical feminist, is right. My argument will not depend on the plausible (or actual) side effects of the prohibition or of normalization of prostitution, which have been widely discussed. Rather, I will only be concerned with the ideals. I will concede to liberals their claim that prostitution is not harmful in and of itself, in the sense that, necessarily, any typical person who works as a prostitute has to be harmed in one way or another ${ }^{4}$. Yet, I will argue that prostitution cannot be thought of as "just another job". Even if prostitution is not harmful in itself in the sense just given, it can do much harm to some individuals. Not all individuals would experience prostitution as a simple exchange of sex for money, or even as an unpleasant job. Many women and men do and would experience prostitution as alienation from their autonomy as individuals - to put it mildly. This, I think, is an important fact that we must not lose sight of: sexual relations simply are not experienced in the same way by everybody.

Liberals could argue that none of those individuals who experience sexual relations in a certain, intimate way should be required to prostitute themselves. Only people who really see prostitution as “just another job” should practice it. I agree with this consideration. However, I think that the consequence of adopting such a policy is the requirement for quite strict regulation, not normalization. If we want to provide the

prostitute as a means, not an end; but the prostitute also uses the client as a means). She is also reluctant to endorse prohibition or abolition. In Estes (2008), however, she argues that prostitution is harmful in itself because it leaves the prostitute cognitively and emotionally confused.

${ }^{4}$ It is also possible to claim that prostitution may be harmful in itself because it necessarily harms society at large. Here, I will not be concerned with this way of understanding the idea that prostitution is harmful in itself. 
means to ensure that people who would not see prostitution as "just another job" do not end up practicing it, then we, as a society, cannot treat prostitution as "just another job”. We have to practice strict vigilance so that no one prostitutes her or himself against her or his genuine will. It is easy for people to end up doing things against their genuine will; apart from direct coercion, there are economic causes, family or peer pressure, and all sorts of forms of manipulation including emotional blackmail, which can result in a person betraying her or his genuine will. The ideal state, therefore, would have to be one in which prostitution were only practiced by those who really wanted to practice it. That would be difficult to achieve. In some similar cases, societies give up and severely restrict or even prohibit certain practices, precisely because of the difficulty associated with checking whether people are actually engaging in them willingly.

\section{The harm}

In a well-known passage from one of her essays, Andrea Dworkin (1997) tells us "what it is like" to be a prostitute in the following words:

She is perceived as, treated as ... vaginal slime. She is dirty; a lot of men have been there. A lot of semen, a lot of vaginal lubricant. ... Her anus is often torn from the anal intercourse, it bleeds. Her mouth is a receptacle for semen, that is how she is perceived and treated. All women are considered dirty because of menstrual blood but she bleeds other times, other places. She bleeds because she's been hurt, she bleeds and she's got bruises on her. When men use women in prostitution, they are expressing a pure hatred for the female body. It is as pure as anything on this earth ever is or ever has been. It is a contempt so deep, so deep, that a whole human life is reduced to a few sexual orifices, and he can do anything he wants. I want you to feel the delicate tissues in her body that are being misused. I want you to feel what it feels like when it happens over and over and over and over and over and over and over again: because that's what prostitution is. The repetition will kill you, even if the man doesn't”. 
There are well-known statistics on the incidence of depression, post-traumatic stress disorder (PTSD), self-hatred and suicide among prostitutes. ${ }^{5}$ Part of what lies behind the statistics is arguably related to marginalization, as well as to stigmatization and to the conditions which surround prostitution; including, in some cases, drug abuse. But it is plausible that some other part is related to how some people experience prostitution ${ }^{6}$. This is where some liberals, who attribute the harm only to marginalization, conditions, and stigmatization, seem to go wrong (see, e.g., Ericsson, 2000; Moen, 2014). Sexual relations are not lived and experienced in the same way by everybody. Some people may accept engaging sex even if they are not particularly "in the mood”; while others may feel bad if they have sex only for the sake of someone else's pleasure. These differences can be extreme: some people may be happy to have sex with someone they are not particularly attracted to if they get something in return, while other people would feel absolutely disgraced by themselves if they had sex and feigned pleasure for the sake of obtaining something else. The latter group clearly attaches more meaning to sexual relationships, irrespective of whether they associate sex with love or not. Statistics also reveal something in this regard. In their Zurich study, Rössler et al. (2010) found that about $40 \%$ of the prostitutes they studied declared that they actually liked the job. Abel similarly comments that "some participants in this [New Zealand] study spoke of being

\footnotetext{
${ }^{5}$ See, e.g., Hoigard and Finstad (1992), Abel (2010) and Rössler et al. (2010). The study by Hoigard and Finstad is controversial because it is said to be biased towards a radical feminist point of view and because it focuses on prostitution on the street and in brothels. However, although the incidence of PTSD, depression, and self-hatred appears to differ depending on the segment analyzed (street, brothel, private, escorts and subsegments thereof), the average incidence of these mental conditions across segments is clearly high (see Rössler et al., 2010 for an interesting study using clusters). It has to be noted, however, that prostitutes in specific segments do appear to be perfectly healthy. In the Zurich study by Rössler et al., this group consists of Europeans working in studios. Weitzer (2005) reports no special incidence of mental health problem among escorts and call girls. These differences are difficult to interpret, as there are many factors involved: the conditions in which prostitution is practiced in the different segments, the differential use of drugs and incidence of drug addiction, general standards of living, etc. However, I think that one factor that could help to explain the fact that some segments are much better off than others in terms of mental health, is that prostitutes in these segments typically choose to do what they do for a living and have more control over their work (Rössler et al., 2010: 150).

${ }^{6}$ In fact, the incidence of drug abuse, especially among street sex workers, may also have to do with how some prostitutes try to cope with what they have to do. The following passage is from an interview in Abel (2010: 209): "Yeah, well I used to take a lot of drugs to do the job. So I mean, when I think about it now, how it's quite horrendous. But a lot of the time I was going through with these men, I actually can't remember, because I was so... There was a big pill scene in Christchurch - you know, barbiturate scene, downers, moggies and valium. Anything to block out basically what you were doing. And then the alcohol on top. (Mandy, Private, Female)". Abel observes that "many street-based workers in this study utilised drugs as a strategy to numb their emotions and perform the role of sex worker" (2010: 209).
} 
naturally promiscuous and therefore argued that the transition into sex work was unproblematic" (Abel, 2010: 183) ${ }^{7}$.

People who attach more meaning to sex would be less inclined to practice prostitution voluntarily, even if they could make more money that way than through any other available job. If such people ever did get to practice prostitution with any continuity, the experience could well be devastating for them, in the way Dworkin describes, leaving a wake of self-hatred and shame in their lives (Rössler et al. (2010) report that mental problems associated with prostitution tend to be long-lasting $)^{8}$. My point, then, is that even if prostitutes were not marginalized and stigmatized, as they no doubt are, the practice itself would surely still have the consequences it has, at least for many people; people who are otherwise perfectly reasonable and typical. This is where I part paths with the standard liberal view, which attributes the high incidence of mental problems of (non-trafficked) prostitutes solely to marginalization, stigmatization and a violent environment (Moen, 2014). The point I want to stress is that it is a fact about sexuality that not all people experience it in the same way. Some people may be happy to have sex with someone who has paid for a very good meal for them; while others may find the very idea disgusting and degrading. Some people need to know and appreciate their partner on several different dimensions before wanting to have sex with them; while other people are enthusiastic about having sex with strangers, or about paying for quick, no-string-attached sex. And some people can even feel disgraced by themselves after having sexual relations which were not really desired-even though perfectly consensual—with a partner they do love ${ }^{9}$. In short, selling sex could be a good option

\footnotetext{
${ }^{7}$ See also Brewis and Linstead (2000).

${ }^{8}$ I do not want to claim that all or only people with a more "monogamous" profile (so to speak) would be harmed by prostitution. Some people with such a profile may be good at detaching themselves from their work; while, in contrast, some more promiscuous people may be unable to make an "unproblematic" transition from casual sex to paid sex. However, I think it reasonable to suppose that prostitution would eventually be harmful to more people with a "monogamous" profile. Incidentally, it could be maintained that it is improper to speak of monogamous or promiscuous profiles, as there are in general no stable profiles. However, it may even be that these two profiles (monogamous and promiscuous) have a genetic and epigenetic basis. Comparisons between the monogamous prairie vole and the promiscuous meadow and montane voles suggests that the expression of certain genes is responsible for the higher levels of oxytocin, dopamine and vasopressin observed in monogamous prairie voles; which seem to account for their high level of attachment to their individual sexual partners (McGraw \& Young, 2010).

${ }^{9}$ Here we could consider a case such as a couple who have not had sex for a month. The women has been willing to have sex all along, while the man, for reasons unknown even to himself, has lost his sexual appetite. However, he feels bad about it and one night he just "tries to be nice", since he thinks he owes it
} 
for many people (provided certain conditions are met); but for many others, it could come close to ruining their lives, as they may live that sex as continuous violation.

As I say above, liberals typically defend prostitution as not being harmful in itself, in the sense that, necessarily, any typical person who works as a prostitute has to be harmed in one way or another. In a recent paper, Ole Martin Moen (2014) discusses ten arguments that could show that prostitution is harmful; and finds them all wanting. I agree with him, and with other liberals, such as Martha Nussbaum (1998), that prostitution in itself, when abstracted from the conditions which surround it, including machismo, classism, and stigmatization, may not be evil in itself: it is not, necessarily, a degradation of the prostitute; it is not, in itself, a form of slavery; and it is not any kind of harmful “deviation”. Typically, liberals compare prostitution to other jobs which share some of the ingredients which can be found in prostitution, such as faking feelings, selling one’s body or selling one’s “soul” (i.e., something which is very intimate) (see Moen, 2014). I am not convinced that it is sufficient to compare acting in the theatre with faking enjoyment in sex (Moen, 2014: 79); or making money out of sharing your most intimate thoughts (as in writing) with making money out of sharing a sexual experience when it is taken to be necessarily intimate. However, even if these comparisons were adequate for the task of evaluating "prostitution in itself", they are clearly not adequate if you shift the focus to comparing how some people might experience these jobs and how they might experience being a prostitute. Faking things when acting in the theatre could be harmful for some people; and sharing intimate thoughts is surely a bad experience for many others. However, I do not think the occasional harm derived from bad experiences in the theatre or as writers are comparable to the harm derived from bad experiences when practicing prostitution (which is the characteristic harm associated with sexual abuse).

It is certainly not easy to come up with examples of jobs that could affect people as badly as prostitution; and it is also difficult to find examples of jobs that so many people could live so badly through ${ }^{10}$. I can imagine, for instance, that being a CEO might be a

to his partner. The experience is a bad one; even though he manages to fake some excitement, he is not aroused at all. From that day on, the problem grows and extends to other parts of his personality.

${ }^{10}$ There are statistics on the incidence of serious mental problems in prostitutes, which, as I mention above, plausibly respond to several factors. There are no statistics on (and plausibly, no way to know about) how prostitution could affect people who have never exercised it and how many people, from the general population, would be harmed if they were to sell sex for a living. Thus, the claim above cannot be 
very bad experience for many people, and that publishing intimate diaries and giving interviews and conferences to promote your intimate publications can eventually be damaging for some. However, I sincerely doubt that the harm is comparable ${ }^{11}$. At the very least, I think that the burden falls on the side of the typical liberal to convince others that the jobs they compare prostitution with can be as harmful as prostitution is. Lars Ericsson (2000) compares prostitution to mining, which is without a doubt a risky activity which typically harms, and can even kill, the people who practice it. There are important and relevant differences between mining and prostitution, though. First of all, mining is equally risky for everybody who can be a miner. In contrast, prostitution is, as I have explained, differentially harmful: for some people it is not problematic, while for other people it could be really harming. This suggests that the policies related to the one case should be different from the policies related to the other. Secondly, the ideal state with respect to mining is one in which the risks are reduced as much as possible: our society should strive to improve miners' working conditions, given that mining seems to be necessary. In contrast, though part of the ideal state with respect to prostitution involves better working conditions, even under improved conditions prostitution may still turn out to be extremely prejudicial for some. It is not clear, therefore, that we should only strive to improve prostitutes' working conditions. Finally, though mining is risky and harmful, it does not entail the personal consequences that often result from prostitution. It is certainly difficult to compare suffering, but I would hazard a guess that a miner, active or retired, can usually live a fulfilling life.

There is another issue that is relevant to harm and prostitution. Suppose it is conceded that some other jobs could be as harmful as prostitution can be. Suppose, for instance, that having to share your most intimate thoughts could leave some people in a state of

but an assumption or a "working hypothesis". I find it plausible that selling sex for a living would not be non-problematic for most of us; and would be surprised if anyone argued against that. Informal talk with prostitutes, with people who work with them, as well as with non-prostitutes, suggests that this assumption is on the right track. Reports from prostitutes and ex-prostitutes, such as Yolanda Estes and Andrea Dworkin, also support the assumption.

${ }^{11}$ Again, I cannot support this claim to the degree of completion felt necessary, as we lack the relevant information. I have to leave it as a plausibility judgment at this stage, motivated by the reports of some prostitutes and ex-prostitutes. (See again the quote above from Dworkin, as well as another report from the BBC page http://news.bbc.co.uk/2/hi/6183491.stm, 6/6/2015: "Prostitution is serial rape of our bodies. From a personal perspective I can say that not just the physical damage but the emotional and spiritual damage caused by prostitution is tremendous and it never goes away. To this day, I have physical problems and my emotional problems will fill a book. When I was in it, getting out seemed impossible because my sense of self-worth was non-existent. I have no solution as long as men pay to do this terrible thing to us”.) 
vulnerability which could lead to personality disorders. It is doubtful whether many of those who would be so harmed actually run the risk of ending up living the nightmare. In general, it seems that the jobs, or practices, that liberals typically mention when they evaluate whether prostitution is harmful in itself, are not jobs or practices that many people could actually be engaged in. Typically, they are jobs that recruit only people who have some kind of vocation towards them. Let me now develop this point further.

\section{More on the harm}

Liberals could respond to my points above concerning harm by reminding me that the discussion is about the ideal we should strive for. In ideal conditions concerning prostitution, people who would be harmed by working in the sex industry simply would not do the job.

My response to this rejoinder is that such ideal conditions cannot be attained by normalization alone. Normalization converts prostitution into just another job with respect to taxes, organization of labor, retirement pensions, unemployment benefits, security measures, and so on; while normalization in a society that does not marginalize and stigmatize prostitutes, converts prostitution into a respectable job. However, normalization, in this or in a more egalitarian society, does not exclude the possibility that people end up selling sex against their will. People who we have agreed should not prostitute themselves for a living, can nevertheless end up doing so due to economic, social or family pressures. In fact, the rate of people who work in prostitution due to debts and other economic needs, as well as to other kinds of factors including being directly coerced (traffic excluded), is quite high (Rössler et al., 2010: 150). Converting prostitution into a respectable job would not avoid this risk.

Again, as a rejoinder, it could be claimed that this risk also exists for every other job. Suppose, as I do above, that being a CEO can have really bad consequences for some people. Surely there are cases of people who should not accept that kind of job but who may end up doing so. If you belong to a super-rich successful business family, there may be a lot of pressure for you to become a CEO of one of the family's companies, even though it may be that your sensitive artistic character is wholly incompatible with the world of CEOs. However, so goes the rejoinder, it is not the business of society as a 
whole to protect sons and daughters of successful entrepreneurs from ending up doing the job their parents want them to do.

Up until now, I have only spoken of one dimension of risk, which we can call the “quality dimension”. The quality dimension of the risk associated with a certain practice has to do with the intensity of the harm that the practice is likely to bring about. I have tried to motivate the idea that not many jobs can be as harmful as prostitution in this respect (even though I am honestly sure that being a CEO can do a lot of harm to some people). However, I agree that this has to be a working hypothesis, as we need to know more about how different jobs can affect different people.

Yet, there is another dimension of risk, which can be called "the quantitative dimension". This dimension has to do with the number of people who could be affected by the harm. For instance, the risk supported by people who would suffer from being CEOs of actually ending up being a CEO, is clearly very low in this dimension. Only a limited number of people can be a position to become a CEO, and most of them are eager to do so. Mutatis mutandis, the same can be said of philosophers, actors or writers; which are all limited professions people almost always choose to go into. In contrast, the risk that someone who should not be a prostitute ends up being one is clearly high. Prostitution is more or less accessible to everyone: no formation is required; the minimal talent necessary does not particularly restrict access; and one does not have to invest much time or money to start. As a result, the proportion of people who could become prostitutes is massive. In this respect, prostitution resembles all other unskilled labor.

So becoming a prostitute, unlike being a CEO, a philosopher or an actor, is easily available to many people. This means that the risk that someone who should not be a prostitute ends up being one is much greater. It is not difficult to imagine how the simple need to make money may force people into prostitution. The combination of the quality and the quantity dimensions of the risk associated with prostitution may well single it out as the most problematic job that any society has to handle. Prostitution can do a lot of harm to many people; and it still could, even if our society was egalitarian and liberal, and did not stigmatize or marginalize prostitutes.

\section{How to avoid the harm: vigilance}


I have argued that normalization would not be enough. Does this mean that we should prohibit prostitution? I do not believe it does. Apparently, many people do not have any kind of problems with having sex for money. They do not experience it as a form of dominance, they do not feel objectified by it (or if they do, they are able to circumscribe such feelings within the practice itself), they do not care much and overall are very happy with the money they make. It is not sensible to accuse such people of false consciousness; and it would certainly seem grossly unfair to tell them that they are not allowed to exercise the trade they have chosen to make their business. However, as a society we have a duty to protect the people who would not be in this situation. We have to ensure that people who would be harmed by prostitution are kept away from it; and this obliges us to consider the issue of how we are to do so.

Peter de Marneffe (2010), based on the argument from harm and on paternalistic premises, defends permissive abolition or extreme regulation. His permissive abolition is a weak variant of the Swedish policy of prohibiting the purchase of sexual services; while his extreme regulation bans kerb-crawling and brothels, and raises the age of would-be prostitutes to 24 . Both policies, according to de Marneffe, are good ways to meet the goal of reducing prostitution drastically and discouraging people, especially immature young people, from entering into prostitution. I am sympathetic to de Marneffe's approach and to his considerations; however, there are two points where I disagree. The first of these is the ultimate goal. The policies de Marneffe recommends may have the results he desires; however, reducing the numbers of prostitutes by making it difficult to practice, is only a part of what needs to be achieved. In the terms I adopt above, in this way we could eventually reduce the quantity dimension of the risk; but we would not touch on its quality dimension. The second point of disagreement concerns the grounding of the policies; de Marneffe grounds his proposal on the defensibility of paternalistic policies aimed at impeding people from harming themselves in certain cases. Let me just note, to begin with, that it is not clear to me that a policy of permissive abolition is a paternalistic policy in the above sense, i.e., a policy aimed at impeding people from harming themselves ${ }^{12}$. In this respect, it is not

\footnotetext{
${ }^{12}$ Abolition laws such as drug or alcohol prohibition may be paternalistic in the above sense, as it can be said that they are aimed at protecting everybody from being addicted and suffering bad consequences. If we were to know that some people would never become addicted or suffer any bad consequences from consuming drugs or alcohol, I wonder whether an unrestricted prohibition law should be considered paternalistic.
} 
comparable to the policy of requiring motorcycle riders to wear a helmet. Restrictive, but unrestricted, policies such as abolition make it equally hard for anybody to enter into the practice of prostitution. That is, it does not discriminate those who would be harmed from those who would not be. The law does not decide only on behalf of those who would run a risk.

However, where I would want to disagree is in the very attempt to ground any prostitution policy on paternalism. Paternalism is always problematic, at least it has been ever since Mill’s On Liberty, where he states:

“The only purpose for which power can be rightfully exercised over any member of a civilized community, against his will, is to prevent harm to others. His own good, either physical or moral, is not a sufficient warrant. He cannot rightfully be compelled to do or forbear because it will be better for him to do so, because it will make him happier, because, in the opinion of others, to do so would be wise, or even right” (Mill, 1859: I.9).

Any policy that regulates what a person does with his/her own life, provided it does not harm others, seems questionable since it does not seem to afford due respect to that person's autonomy; and that is especially so if the policy is forced on people who would not be harmed. Requiring people to wear a helmet, or forbidding suicide in certain circumstances, might be defensible: everybody runs the risk of having an accident-and wearing a helmet is a small price to pay-and it can be argued that everybody who is in certain circumstances (not terminally ill, for instance) is better off alive than dead. Paternalism seems to be a bad policy if it is not the case that everybody affected by the paternalistic law is saved from an actual danger. It is, thus, more straightforward and acceptable, to argue for restrictive policies on non-paternalistic grounds. I think that it is perfectly possible to argue for restrictive policies while maintaining that anybody has the right to do what they really wish to do in their sex life.

I want to argue that a policy of vigilance is the most adequate policy to adopt with respect to prostitution. A policy of vigilance is a policy that attempts to discriminate between those who take a certain course of action willingly and those who do not. It puts no restraints on those who exercise their genuine will; but it protects those who are openly or subtly coerced. Liberal societies regularly apply this kind of policy in delicate 
cases such as euthanasia or living organ donation. Donating a living organ, such as a kidney, is directly harmful in a way that prostitution is arguably not. Even if the harm is compensated by the happiness derived from having helped someone live ${ }^{13}$, the harm and the risk are still inherent. However, the analogy between living organ donation and prostitution lies elsewhere. Living organ donation is available to many people: anybody could donate an organ in principle. This generates the (quantitative) risk that some people donate against their will. People may be offered money to donate an organ; and some people may accept because they need the money. People can also be "convinced" by relatives that they should donate an organ to someone in the family; and a boss could equally "convince" an employee that donating a kidney to save his or her child is what the employee should do, etc. To avoid situations like these, our societies have chosen to be hypervigilant. In some countries, it is simply forbidden to donate living organs outside the family. In others, like the US, anonymous donation is possible. Yet, the premises under which living donation in general is admitted are that " $[t]$ he person who gives consent to be a live organ donor should be competent, willing to donate, free from coercion, medically and psychosocially suitable, fully informed of the risks and benefits as a donor, and fully informed of the risks, benefits, and alternative treatment available to the recipient” (from the Consensus Statement on the Live Organ Donor, 2000). The document which develops these premises establishes a protocol to guarantee that donors fulfill the established requirements (see https://www.kidney.org/sites/default/files/docs/jama_article.pdf).

This, I submit, is a case where our society exerts hypervigilance. I think a similar case is that of euthanasia, where it is legal. In societies that permit euthanasia, it is necessary to ensured that the decision to die stems from the uncoerced, fully informed and healthy will of patients.

Liberals like to compare prostitution to other jobs. I think it is more appropriate to widen the scope and compare it to other practices in general. Prostitution certainly is a job, at least in the sense that money is obtained for services rendered. However, in some respects it is more analogous to other practices. I have maintained that the risk of harm

\footnotetext{
${ }^{13}$ See Smith and Davidson (2014) on the happiness derived from giving, also in these cases.
} 
associated with prostitution is especially significant, and so prostitution should be dealt with in the same terms as we deal with other practices that we deem to be especially risky. It is all too easy for people to get into prostitution against their genuine will; they may need the money simply to survive or to pay off debts, or they may be coerced in some way. However, the experience can certainly be devastating. The ideal state, I submit, is one in which only those people who will not be harmed as a result of practicing prostitution become prostitutes. This ideal state cannot be achieved by normalization, but it can by vigilance; and vigilance does not compromise anybody's rights: customers and prostitutes who have no problem in exchanging sex for money are free to do so ${ }^{14}$.

The vigilance I defend, by its very nature, imposes some restrictions on age. If the goal is to allow only those people to do $x$ who are competent at $x$-ing, willing to $x$, free from coercion, psychosocially suitable, and fully informed of the risks and benefits of $x$-ing, then it is probably not enough to be 18 to $x$. When applied to prostitution, vigilance may also forbid pimping, since pimping facilitates coercion. However, these are issues which should be discussed further, once it is agreed that the best policy towards prostitution is one of vigilance. On the other hand, objectors may protest that vigilance is not a feasible policy, and that it is too demanding on would-be prostitutes and on society as a whole. My response to this argument is that the potential harm is great and that, in cases where great harm is considered, we do implement policies of vigilance effectively.

\footnotetext{
${ }^{14}$ An anonymous referee points out that my text might suggest a better solution: given that some segments of working prostitutes clearly fare much better than others in terms of PTSD, depression, etc., and that I myself suggest that this may be due to their having more control over their work, maybe the best solution would be to restrict the practice of prostitution to those segments (e.g., escorts and call girls). I think that this kind of result might be a consequence of applying the policy I recommend. I want to maintain that only people who really want to work as prostitutes should do so; and also that they should be autonomous while they work as prostitutes. If only escorts and call girls meet these conditions, then prostitution will be restricted these segments, but only as a result of applying the general policy I recommend (that is: general principles come first). It should, however, be noted that many prostitutes prefer to work in the street (Abel, 2010). I see no motivation for not allowing them to do so, as street prostitution is not necessarily harmful. The statistics reveal greater incidence of PTSD, depression, etc. among prostitutes who work the street, because it is more stigmatized, more marginal, more related to drug use and abuse, and a larger proportion felt forced to begin and to continue. A liberal policy with strict vigilance may alleviate this situation, without the need to prohibit street prostitution; which, as numerous studies show, is extremely difficult to eradicate, while prohibition makes life worse for prostitutes (e.g., Kilvington et al., 2001).
} 
It may be said that it is not clear whether I am approaching the issue from a utilitarian or a liberal perspective ${ }^{15}$. On the one hand, I insist on the harm that prostitution may cause, and thus it seems that I aim to find a policy that would minimize such harm. On the other hand, I use liberal notions such as autonomy, and claim that the aim of the policy of vigilance should be to ensure that only people who really want to be prostitutes engage in sex work. The problem, then, is that the proposed policy of vigilance may fail to stop some people who will be harmed by prostitution from exercising it; since the policy only attends to whether prostitution is a real choice or not. This is a very interesting point. I think that the ultimate goal of any policy concerning prostitution must in general be to minimize harm. Radical feminism maintains that harm is effectively minimized only if prostitution disappears; whereas the typical liberal position claims that harm is minimized by treating prostitution as just another job in all respects (including how society sees it). The vigilance policy I propose holds that the liberal policy is insufficient, but there is the risk that by stressing the importance of autonomy, this policy is less efficient (in terms of reducing harm) than a policy which, for instance, incorporates some means to try to determine whether the person who wants to work as a prostitute is such that he/she may suffer if he/she engages in sex work.

The policy I propose could be complemented in one of two ways. The first would be, as suggested by the last sentence in the previous paragraph, to make use of personality tests and some kind of social/psychological screening to decide who is likely to be harmed by working in the sex industry. This would be in fact be a paternalistic correction or supplementation to the vigilance policy; for it would mean that some people would not be allowed to do what they report that they want to do. Yet, the main problem related to this kind of policy is that it would be extremely hard to implement: it is difficult, to say the least, to predict whether a person who declares a desire to do something would in fact be harmed by doing it $^{16}$.

\footnotetext{
${ }^{15}$ Thanks to an anonymous referee for pointing this out.

${ }^{16}$ I myself suggested above that there may be a profile of person who tends to be more harmed by prostitution. I think that it is prima facie reasonable to believe that what I have called a person with a more "monogamous" profile would suffer more. However, what we would need in order to prevent somebody from working as a prostitute is real knowledge; and clearly we lack that kind of knowledge. We could manage to get some ideas as to what profiles or groups of people are more at risk than others, but I take it that this is not enough to prevent an individual from doing what they say they want to do.
} 
The second way to complement the vigilance policy would be to make it extremely easy for people who may be harmed by prostitution to leave. One of the problems that prostitutes currently face is that it is not easy for them to leave the sector. The causes are varied: it is not easy to find another job which pays as well; prostitutes seem to carry the associated stigma with them wherever they go; drug abuse makes it almost impossible for many to step outside the circle once they have entered; and so on. To remedy this situation, we should offer prostitutes who want to leave the job realistic options, realistic help and proper integration. If we were able to do this, that is, if the exit door is always open, then there might be no need to place any restrictions on the autonomy of individuals, and it would be possible to let people do what they really want to, without having to worrying too much about the harm we do not prevent. In short, a good policy of vigilance, plus a good policy with regard to exiting the sector, could be a good harmminimizing, yet liberal autonomy-respecting, policy ${ }^{17}$.

When societies, for one reason or another, believe that vigilance is not feasible, they lean towards extremely restrictive policies, or even prohibition. For instance, a case can be made against regulating, instead of prohibiting, euthanasia based on the difficulty of discerning the real will of a patient. Thus, if for whatever reason it is thought that a policy of vigilance towards prostitution is not possible, then we might reconsider extremely restrictive policies. However, the case for these policies, which would impose restrictions on the rights of some individuals, would not be paternalistic. The case would be based on the harm that not imposing such restrictions would cause: if, because of wanting to preserve the rights of some individuals, prostitution is allowed, then some or perhaps many people will be harmed.

Yet, an extremely restrictive policy is not the ideal state with respect to prostitution; at most it could be a satisfacing solution. And, although I said at the start that I would not be concerned with side effects in this paper, we know what kind of consequences extremely restrictive policies tend to have. This is indeed a powerful reason to struggle to bring about the ideal, vigilant, state.

\section{Conclusion}

\footnotetext{
${ }^{17}$ It could be argued, however, that if someone really wants to do something, and to continue doing it, then it is unlikely that he/she would be as harmed by doing that as someone who was forced to do it.
} 
Over the last two decades, some countries have implemented legalization policies (e.g., the Netherlands and Germany), while others have passed laws abolishing prostitution (e.g., Sweden) or maintain a policy of prohibition (e.g., most of the US). Legalization policies like those implemented by Germany or the Netherlands, normalize and regulate prostitution through licensing sex workers and establishments in certain zones. This kind of policy gives society as a whole a sense of control, but is ultimately ineffective, because the supply (and the demand) is greater than what is legally permitted. It also does nothing to prevent the exploitation of workers by brothel owners (Scambler and Scambler, 1997). Even more liberal policies, such as the New Zealand full decriminalization laws, still fail to eradicate coerced and harmful sex work. Gillian Abel (2010, 2014) reports that sex work is now safer in New Zealand and that the human rights of prostitutes have been improved. However, a decriminalization policy does not attend at whether prostitutes are doing what they do willingly. Throughout this paper I have insisted that prostitution can be a very harmful practice, especially if it is not exercised as the result of a genuine choice (see fn. 15 above). I have claimed that the ideal state of affairs with respect to prostitution is one in which prostitution can be exercised freely, but in which society implements protocols to try to make sure that prostitution is indeed a free choice. It will be extremely tricky to design and implement those protocols, but I hope that I have been able to demonstrate the need to try to work in that direction. Implementing a policy of vigilance is arguably part of the ideal state, but it is also a policy that is needed in the present circumstances. None of the policies that have been implemented so far seems to take into account that prostitution can be differentially harmful, which appears to me to be a glaring omission. A policy of vigilance, complemented by a policy of support of prostitutes who want to leave the sector, looks like a fair policy that our societies could try to implement; a policy whose immediate goal would be to reduce the number of prostitutes who work in the sector against their will.

\section{Acknowledgments}

Thanks to Lorenz Lauer, Antonio Casado da Rocha and especially to Javier Peña Echeverria, who discussed with me previous versions of this paper. Thanks also to two anonymous referees provided by Ethical Theory and Moral Practice, who helped me to improve the paper more than significantly. Funding for this paper was provided by 
Research Grant FFI 2014-52196-P of the Spanish Ministry of Economy and Competitiveness (MINECO).

\section{References}

Abel, G. (2010) Decriminalisation: A harm minimisation and human rights approach to regulating sex work, PhD Thesis. Christchurch: University of Otago.

Abel, G. (2014) A decade of decriminalization: Sex work 'down under' but not underground, Criminology and Criminal Justice, 14: 580-592

Barry, K. (1995) The prostitution of sexuality: the global exploitation of women, NewYork and London: New York University Press.

Brewis, J. and Linstead, S. (2000) "The worst thing is the screwing" (2): Context and career in sex work, Gender, Work and Organization, 7: 3, 168-180

de Marneffe, P. (2010) Liberalism and prostitution, Oxford: Oxford University Press

Dworkin, A. (1997) Prostitution and male supremacy, in A. Dworkin, Life and Death, New York: Free Press, pp. 138-216.

Ericsson, L. O. (1980) Charges against prostitution: an attempt at a philosophical assessment. Ethics, 90: 38-9.

Estes, Y. (2001) Moral reflections on prostitution, in Essays in Philosophy, 2 (2): The Philosophy of Love and Sex. Mississippi State University.

Estes Y. (2008) Prostitution: a subjective position, in A. Soble and N. Power (eds.) The philosophy of sex: contemporary readings. 5 edn. Lanham, Maryland: Rowman and Littlefield, pp. 353-65.

Farley M. (2004) "Bad for the body, bad for the heart”: prostitution harms women even if legalized or decriminalized. Violence Against Women 10:1087-125.

Hoigard, C. \& Finstad, L. (1992) Backstreets: Prostitution, Money, and Love. University Park: Pennsylvania State University Press.

Kilvington, J., Day, S. and Ward, H. (2001), Prostitution policy in Europe: A time of change? Feminist Review, 67: 78-93.

Moen, O. M. (2014) Is prostitution harmful? Journal of Medical Ethics, 40 (2): 73-81.

McGraw, L.A. and Young, L.J. (2010) The prairie vole: an emerging model organism for understanding the social brain. Trends in Neurosciences. 33:103-109. 
Mill, J.S., (1859) On Liberty, Indianapolis: Bobbs-Merrill, 1956.

Nussbaum M. (1998) “Whether from reason or prejudice”: taking money for sexual Services. J Legal Stud 27:693-723.

Rössler W., Koch U., Lauber C., Hass A.-K., and Altwegg M., Ajdacic-Gross, V., \& Landolt, K. (2010) The mental health of female sex workers, Acta Psychiatrica Scandinavica, 122: 143-152.

Smith, C. \& Davidson, H. (2014) The paradox of generosity: giving we receive, grasping we lose, New York: Oxford University Press.

Sullivan, M. (2007) Making sex work: A failed experiment with legalised prostitution. Melbourne: Spinifex.

Scambler, G. and Scambler, A. (1997) Afterword, in G. Scambler and A. Scambler (eds.), Rethinking prostitution: Purchasing sex in the 1990s. London, New York: Routledge.

VV.AA. (2000) Consensus Statement on the Live Organ Donor, Journal of the American Medical Association (JAMA), December 13,-—Vol 284, No. 22

Weitzer, R. (2005) New directions in research on prostitution, Crime, Law \& Social Change, 43: 211-235. 